\title{
Update on Pregnancy in Chronic Kidney Disease
}

\author{
Giuseppe Castellano Vincenzo Losappio Loreto Gesualdo
}

Nephrology, Dialysis and Transplantation Unit, University of Bari, Bari, Italy

\author{
Key Words \\ Pregnancy · Chronic kidney disease $\cdot$ Dialysis · Kidney \\ transplantation
}

\begin{abstract}
The occurrence of pregnancy in patients with chronic kidney disease (CKD) has been considered a dangerous event both for the mother and for the fetus. However, increasing evidence shows that the stage of CKD is the leading factor that can predict possible acceleration in the declining of renal function and complications of pregnancy. This review summarizes recent data on pregnancy in patients with CKD, dialysis and kidney transplantation.
\end{abstract}

Copyright $\odot 2011$ S. Karger AG, Basel

\section{Discovery of Renal Dysfunction during Pregnancy}

Pregnancy is probably the major physiologic event that can induce profound changes in renal function. The glomerular filtration rate (GFR) as well as the local production of erythropoietin and vitamin $\mathrm{D}[1,2]$ increase by more than $50 \%$. The increase in GFR is due to an augmented renal blood flow, not to an increased intraglomerular pressure [3]. However, in the presence of chronic kidney disease (CKD), this physiological adaptation is reduced or absent [1]. Therefore, a woman with undiagnosed renal dysfunction might present the first symptoms and signs during pregnancy.

\section{KARGER \\ Fax +4161306 1234 \\ E-Mail karger@karger.ch}

www.karger.com
(C) 2011 S. Karger AG, Basel

1420-4096/11/0344-0253\$38.00/0

Accessible online at:

www.karger.com/kbr
First, it is important to realize that the measurement of renal function in pregnant women is still not standardized. Given the increase in GFR, the concentration of serum creatinine usually falls to $0.4-0.6 \mathrm{mg} / \mathrm{dl}$ (35-55 $\mu \mathrm{mol} / \mathrm{l})$. This event does not occur in patients with renal dysfunction, where a level of serum creatinine around 1-1.2 mg/dl (90-110 $\mu \mathrm{mol} / \mathrm{l})$ could be considered physiologic [4]. On the contrary, these values should be seen as the first signs of renal dysfunction. In addition, the use of the Modification of Diet in Renal Disease (MDRD) and Cockcroft-Gault formulas has never been validated in this population [5]. In a study on 209 women with preeclampsia [6], the Cockcroft-Gault formula overestimated the GFR by approximately $40 \mathrm{ml} / \mathrm{min}$, whereas the MDRD formulas underestimated the GFR (by $19.68 \mathrm{ml} /$ min for the full MDRD and by $12.6 \mathrm{ml} / \mathrm{min}$ for the modified MDRD). Therefore, the gold standard for GFR estimation in pregnancy is still considered to be the 24-hour urine collection for creatinine clearance [7].

Once renal dysfunction has been identified, the family doctor should refer the patient to the nephrologist, who would start a clinical and biochemical monitoring throughout the pregnancy. The frequency of the monitoring should increase with the progression of pregnancy, including the measurement of the mother's renal function, analysis of the urine, and blood pressure. Renal ultrasound should be performed. Methods for measuring proteinuria should be the urine protein-to-creatinine ratio or, in the presence of equivocal results, the 24-hour collection can be considered [8]. The monitoring of pro- 
teinuria is very relevant to the diagnosis of preeclampsia and in patients with a history of proteinuric kidney disease such as glomerulonephritis.

\section{Factors Influencing the Acceleration of CKD}

\section{Pregnancy in Patients with a History of CKD}

There is increasing evidence indicating that a certain degree of renal insufficiency is associated with an increased risk for accelerated decline in renal function. Serum creatinine levels equal to or higher than $1.4 \mathrm{mg} / \mathrm{dl}$ $(130 \mu \mathrm{mol} / \mathrm{l})$ led to a more rapid progression of chronic renal failure in pregnant than in nonpregnant women with similar degrees of renal dysfunction $[2,9]$. Considering patients with diabetic nephropathy, women with serum creatinine levels of $1.4 \mathrm{mg} / \mathrm{dl}(130 \mu \mathrm{mol} / \mathrm{l})$ or greater, measured before pregnancy or in the first trimester, showed an accelerated progression of the renal disease [10]. Two studies showed that women with an initial serum creatinine level equal to or higher than $2 \mathrm{mg} / \mathrm{dl}$ (180 $\mu \mathrm{mol} / \mathrm{l})$ experienced a significant incidence of preterm delivery, preeclampsia and accelerated decline in renal function during or immediately after pregnancy $[11,12]$. Imbasciati et al. [13] recently analyzed women with stages 3-5 CKD. No differences were found in the GFR before and after delivery in the entire cohort of women with a serum creatinine level of $1.5 \mathrm{mg} / \mathrm{dl}(140 \mu \mathrm{mol} / \mathrm{l})$. Unlike this, an accelerated rate of GFR loss after delivery was observed in the subgroup of women with both an estimated GFR of $40 \mathrm{ml} / \mathrm{min} / 1.73 \mathrm{~m}^{2}$ and proteinuria of $1 \mathrm{~g} /$ day before pregnancy. These data clearly indicated that pregnancy should be avoided in this group. Therefore, in diabetic nephropathy and in other renal diseases, the level of renal function at the time of conception is pivotal to establish the possible effects on the progression of the disease. A very recent study also showed that the presence of $\mathrm{CKD}$, as early as at stage 1 , was associated with an increased rate of preterm delivery (44 vs. $5 \%$ ), cesarean section (44 vs. $25 \%)$ and need for neonatal intensive care (26 vs. $1 \%)$. In addition, the authors demonstrated that the differences between the two groups were highly significant already at CKD stage 1 [14].

\section{Hypertension}

Hypertension is very common in conceiving women with renal disease [2]. In human pregnancy, hypertension has been associated with decreased uteroplacental blood flow. An animal model of hypertension in pregnancy nicely showed the presence of a 'pathogenic feedback' be- tween systemic hypertension and placenta, with alteration in the physiology of the fetus $[15,16]$. By using an in vivo model, it has been demonstrated that maternal hypertension differentially alters placental structure and gene expression. The different grade of hypertension (mild or moderate) affected the placental functional capacity and, interestingly, contributed to programming of hypertension in adult offspring. In late gestation, the placental blood flow was significantly reduced in the moderate hypertension group, whereas mild hypertension resulted in an increase in placental efficiency, without significant changes in the placental blood flow. Profound alterations in the genes of the renin-angiotensin-aldosterone system were indeed identified $[15,16]$.

However, all antihypertensive drugs can be used to manage hypertension except ACE inhibitors or sartans. These drugs, which are frequently prescribed for their nephroprotective effect, appear to be related to an increased number of congenital malformations such as oligohydramnios, fetal growth retardation, neonatal death due to renal failure or hypotension $[4,17,18]$. There is no evidence that the possible suspension of these drugs during pregnancy can have an effect on the course of the maternal kidney disease.

\section{Infections}

Infections are common in women with renal disease during pregnancy. There is some evidence showing that the accelerated decline in renal function was triggered by urinary tract infections [2].

\section{Preeclampsia}

Preeclampsia is characterized by elevated blood pressure, proteinuria and edema, and complicates $5-8 \%$ of pregnancies $[19,20]$. The risk factors for this condition are different, such as the advanced age of the mother, nulliparity, glomerulonephritis, diabetes, hypertension and obesity. Recent studies in patients have identified alterations in circulating angiogenic factors, in the renin-angiotensin system, and insulin resistance that might contribute to placenta ischemia $[4,21]$.

Studies of gene expression on the placenta from patients affected by preeclampsia indicated the presence of unbalanced expression between angiogenic and antiangiogenic factors [4, 22-24]. Molecules such as soluble fms-like tyrosine kinase 1 have been described to play a pivotal role in the endothelial dysfunction occurring in preeclampsia [21]. Interestingly, these new molecules have also been tested as candidate biomarkers for preeclampsia. However, despite the numerous independent 
studies performed on these new potential biomarkers (placental growth factor in the first trimester; fms-like tyrosine kinase 1 or soluble endoglin in the second trimester), to date the screening for early detection of preeclampsia is still not possible in the clinical setting.

Up to now, little is known on the role of preeclampsia as a risk marker for subsequent end-stage renal disease. Vikse et al. [25] have recently analyzed a cohort of women who had had a first singleton birth between 1967 and 1991, including data from up to 3 pregnancies. They showed that among women who had been pregnant one or more times, preeclampsia during the first pregnancy was associated with a relative risk of end-stage renal disease of 4.7. These data, together with other interesting findings, demonstrated that preeclampsia is a marker for an increased risk of subsequent end-stage renal disease.

Despite several trials examining various interventions, no strategy has proven to be effective in the prevention or treatment of preeclampsia other than delivery of the fetus. Complications include maternal stroke, renal failure and placental abruption. Data in animal models indicated that the antagonism of vascular endothelial growth factor (VEGF) signaling by fms-like tyrosine kinase 1 occurs during preeclampsia. Gilbert et al. [26] demonstrated that chronic infusion of VEGF(121) during late gestation restored the GFR and endothelial function, decreasing the blood pressure associated with placental ischemia. Therefore, VEGF(121) may be a candidate molecule for the management of preeclampsia and its related complications.

Considering the drugs currently available, low-dose aspirin has been shown to have a small but significant effect on the prevention of preeclampsia [27]. This treatment seems to be safe and should be given to women who present risk factors for the development of preeclampsia. The dietary supplementation of calcium, folic acid or Larginine has been suggested. However, randomized controlled trials are needed to support these initial observations [4].

\section{Glomerulonephritis}

A recent study by Limardo et al. [28] investigated the long-term outcome of kidney disease in women with IgA nephropathy and preserved kidney function, who did and did not become pregnant. As many as 223 women (136 and 87 in the pregnancy and nonpregnancy groups, respectively) had serum creatinine levels $\leq 1.2 \mathrm{mg} / \mathrm{dl}$ (110 $\mu \mathrm{mol} / \mathrm{l})$ at diagnosis. The results indicated that pregnancy in IgA patients did not affect the long-term outcome of kidney disease. Similar results were reported in two studies showing that pregnancies in patients with $\mathrm{He}-$ noch-Schönlein purpura were complicated by proteinuria and/or hypertension, even in the absence of active renal disease [29-31].

Several studies investigated the effects of pregnancy in patients affected by systemic lupus erythematosus (SLE) [32]. Despite the great improvements in the survival of the mother and the fetus in the last few years, pregnant patients with SLE may still experience several complications. SLE is characterized by normal fertility that can be affected by treatment (e.g. cyclophosphamide) or by severe renal dysfunction. However, pregnancy in SLE patients is associated with thromboembolisms, fetal loss, hypertension, and preeclampsia [33]. Maternal mortality is more than 20 -fold higher compared to the healthy population, with an odds ratio of 1.7 for cesarean section and 3.0 for preeclampsia $[34,35]$.

Renal flares in pregnant patients with SLE seem to occur in specific conditions, especially when active disease is present at the moment of conception [33,36]. Another important factor to consider is the class of lupus nephritis. Classes III and IV are more associated with hypertension and preeclampsia compared to classes V and II [37]. The differential diagnosis of preeclampsia from a lupus flare is a major problem in pregnant SLE patients. As a first-line approach, autoantibody levels and analysis of urinary sediment should be performed to differentiate the disease. In addition, C3 and C4 levels, lupus anticoagulant and antiphospholipid antibodies should be tested. In fact, the presence of lupus anticoagulant is strongly associated with the development of preeclampsia.

The presence of hypertension, proteinuria, antiphospholipid syndrome and thrombocytopenia at the moment of conception is also associated with a poor fetal outcome in pregnant women with SLE [32]. With the improvement of therapeutic strategies over the last few years, fetal loss has decreased from $40 \%$ in 1960 to $17 \%$ in 2000 [33]. As a treatment that may help reduce such complications, acetylsalicylic acid was shown to lower the incidence of preeclampsia in SLE perinatal death with an increase in the birth weight [33].

Therefore, data from the literature suggest that the SLE activity should be monitored at least for 6 months before conception and that pregnancy should be started with no signs of active lupus nephritis. If these conditions are not present, then contraception should be strongly suggested to the patients. 


\section{Pregnancies in Dialysis Patients}

\section{Hemodialysis}

Pregnancy is a challenge for women with end-stage kidney disease, especially for dialysis patients [38]. However, nowadays the massive improvements in maternalfetal care and in dialysis efficiency, frequency, and support therapy allow them to reach previously inaccessible targets $[1,39]$. There are few data about the conception rate for this population of women, and most of them are from old databases, spread in different countries. Data from the EDTA and national registries demonstrated a conception rate between 0.3 and $0.75 /$ year/patient [ 40 43].

The analysis of these databases clearly showed that the rate of healthy newborn children, from women who are on dialysis, raised from $20-23 \%$ in the 1980 s to $75 \%$ today, with an improvement also in the management of clinical problems $[1,14,44,45]$.

\section{Outcome}

Conception and positive outcome of the pregnancy are much more frequent when women have residual renal function, with a better prognosis for pregnancies that began before starting dialysis. Giatras et al. [46] observed that $47 \%$ of pregnancies in their population were successful during the first 2 years of dialysis, while women with 10 years of treatment had only 6 newborn babies out of a total number of 120 pregnancies.

Starting dialysis during pregnancy is related to a better fetus survival, almost $30 \%$ higher than the one observed in women under dialysis for years [42, 47]. There are some case reports of pregnancies in women with a 10 -year history of dialysis $[41,48]$ but the birth of healthy newborns was extremely uncommon in these women $[48,49]$.

In light of the heterogeneity of the data coming from the literature, any attempt to correlate outcomes with dialysis therapy is hazardous; however, the best results are reported in settings of long daily dialysis, suggesting that dialysis efficiency may play an important role [50-52]. Recent evidence showed that after the 16th-20th week, the cumulative dialytic dose should be increased from 3 sessions/week to daily treatments. A better outcome, for the fetus, was reached with $24-28 \mathrm{~h}$ of dialysis per week [53].

In 2004, Gangji et al. [54] reported a case where conventional hemodialysis was switched to nocturnal hemodialysis in a patient with uncontrolled hypertension. The pregnancy ended with a natural delivery of a healthy, '38-week-old' infant. In 2005, Haase et al. [52] presented their observations on women treated with an intense hemodiafiltration protocol of 24-36 h/week with improved fetal outcomes. Also, Barua et al. [50] reported their successful results on nocturnal home hemodialysis. This therapeutic indication for long-lasting dialysis is confirmed by the actual literature [14] and allows the physicians to manage, in a better way, some clinical issues related to these kinds of pregnancies like hypertension and polyhydramnios $[2,4,50,54-56]$.

Despite the progressive improvements, in about 50\% of pregnant women on dialysis pregnancies do not end with the birth of a healthy child, and neonatal mortality is higher than the one observed in the general population, with a higher rate of early delivery, a mean gestational time of 32 weeks and a lower weight at birth [14, 53, 57, 58].

\section{Malnutrition}

Data from the literature indicate that malnutrition is particularly common in pregnant hemodialyzed women. For this reason, it is necessary not to limit the daily calorie intake to $1.2-1.3 \mathrm{~g} / \mathrm{kg} /$ day of proteins. Particularly, there is the need of $1 \mathrm{~g} / \mathrm{kg}$ related to a sufficient mother intake and a supplementary one of $20 \mathrm{~g}$ /day necessary for a correct development of the fetus $[2,59]$. Some authors even suggest a $1.8 \mathrm{~g} / \mathrm{kg} /$ day protein intake [46]. According to these suggestions there are some case reports about intradialytic hyperalimentation as adjuvant support in pregnant hemodialysis patients [60].

\section{Peritoneal Dialysis}

Peritoneal dialysis is characterized by a lower rate of pregnancies, about $50-70 \%$ less than the one observed in the hemodialysis population, with important issues related to the maintenance of a good nutritional asset [61, 62]. Despite the low number of pregnancies, peritoneal dialysis seems to have a better outcome if compared to hemodialysis with a higher rate of live newborn babies. This result may be related to residual renal function and to the less traumatic and more paraphysiologic depurative action of peritoneal dialysis [63].

\section{Pregnancy in Transplantation Patients}

KDIGO guidelines suggest that women should not become pregnant at least 1 year after transplantation. In addition, pregnancy should only occur if kidney function is stable with a proteinuria lower than $1 \mathrm{~g} /$ day. For a successful pregnancy, the history of renal dysfunction is also 
important: a serum creatinine level greater than $1.5 \mathrm{mg} /$ $\mathrm{dl}$ before transplantation is related to an increased risk of irreversible graft loss during pregnancy [2]. Moreover, this risk of graft loss is lower with a better renal function at the time of conception [59,64-67]. Other experiences suggest a deleterious effect of pregnancies on graft function in patients with a serum creatinine level of $1.75 \mathrm{mg} /$ $\mathrm{dl}(160 \mu \mathrm{mol} / \mathrm{l})$ and a greater risk for patients with a prepregnancy creatinine level of $200 \mu \mathrm{mol} / \mathrm{l}$ [68]. There is a consensus that waiting more than 2 years after transplantation ensures a better graft survival [68]. However, there are pregnancies even during the first year after transplantation [69].

There are different clinical complications related to a pregnancy after solid organ transplantation. According to the data presented by the National Transplantation Registry in 2004, hypertension is reported with a rate from 47 to $73 \%$ in women during pregnancies which occurred after kidney transplantation [70]. The mean birth weight of infants of mothers receiving calcineurin inhibitors (CNIs; cyclosporine and tacrolimus) is reported to be $2.1-2.5 \mathrm{~kg}$ with a mean gestational time of 35 weeks instead of 37 weeks observed in CNIs-free immunosuppressive protocols. Hypertension occurring in this population might explain these data, and may require a more aggressive treatment [70-73].

Preeclampsia also seems to be related to the low birth weight, the reduced duration of gestation and the increased risk of developing hypertension. Almost one third of pregnant women receiving a kidney or combined kidney-pancreas is reported to develop preeclampsia [70]. According to medical indications, deliveries are more likely to be performed by cesarean section [73].

\section{Immunosuppression and Pregnancy in Kidney}

Transplant Recipients

The most challenging part of the follow-up during pregnancy is tailoring the immunosuppressive strategy. There is the experimental evidence that mTOR inhibitors are embryotoxic or fetotoxic in rats [74]. Recent studies suggest a pivotal role for mTOR inhibitors in embryo implantation [75]. According to the literature, mTOR inhibitors should be stopped or replaced before pregnancy with azathioprine (KDIGO 2009). Data from the National Transplantation Pregnancy Register showed 2 patients, whose therapy with sirolimus was switched to azathioprine during the first trimester, and who gave birth to children in the 36th and the 38th week of gestation with a birth weight of 2,637 and 3,076 g, respectively, while 2 cases of pregnancies without discon-

Update on Pregnancy in Chronic Kidney Disease tinuation ended with spontaneous abortions in the 8th and 6th week [76].

Few data are found in the literature about female recipients with sirolimus exposure during pregnancy; Guardia et al. [75] reported a successful pregnancy under sirolimus-based immunosuppression $[77,78]$. Due to this shortness of data related to controlled studies in women, mTOR inhibitors are categorized as 'C' by the FDA [73].

A first look at the outcomes in CNI-treated female kidney transplant recipients with an interval from transplant to pregnancy greater than 5 years showed a favorable risk profile for the newborn, the recipient and the graft. There were no maternal or fetal deaths, no rejection was observed during pregnancies and serum creatinine levels remained stable during and after pregnancy. The only negative evidence, compared to the normal population, was a higher incidence of spontaneous abortion (23.5 vs. $16 \%)$ [79].

Reducing the risk of rejection is possible by keeping appropriate blood levels of CNIs. According to data reported in the National Transplantation Pregnancy Register, pregnant kidney transplant recipients who maintained stable function during their pregnancies took higher doses of cyclosporine before and during pregnancy than patients who had renal dysfunction [80]. Based on the use of tacrolimus, Jain et al. [79] reported 21 pregnancies with decreased trough levels for kidney and kidney-pancreas recipients with no rejection episodes. Available reports indicate a similar rejection rate between the transplant recipient population with and without pregnancies $[70,82]$.

There is a higher concern for the safety of the child. CNIs cross the placenta entering the fetal circulation [83] and there is evidence that fetus trough levels are half the mother's ones [84, 85]. It is obvious that there is the possibility of fetotoxic and teratogenic effects. All the data collected in the literature came from observational studies in humans and evaluation of the gestation in rodents.

CNIs are not related to any pattern of congenital malformations in rodents and there is evidence of growth delay, cataracts and fetotoxic effects at high doses $[56,74$, 86]. Regarding structural malformations in children of transplant recipients receiving CNIs, the incidence of malformations remains low and the prevalence of major structural malformations is similar to that in children of healthy women [87]. Taking into account the available data, CNIs received the 'C' class category by the FDA because human risk cannot be ruled out, since studies on humans are lacking and studies on animals are either positive for risk or lacking evidence [73].

Kidney Blood Press Res 2011;34:253-260 257 
The same ' $C$ ' class category is assigned to mycophenolate mofetil, in both its formulations, by the FDA [73]. The KDIGO recommendation is to stop or replace mycophenolate mofetil before pregnancy is attempted. The European Best Practice Guidelines in 2002 suggested stopping mycophenolate mofetil 6 weeks before the attempt to conceive. This suggestion was given according to data, revealed by manufacturers, about structural malformations in offspring of animals exposed to mycophenolate mofetil during pregnancy [82]. In 2004, Le Ray et al. [74] reported the case of a newborn whose mother received mycophenolate mofetil during pregnancy developing multiple malformations similar to the ones observed in animal models [80]. A 2006 report of 18 kidney recipients observed 26 pregnancies under mycophenolate mofetil with 11 spontaneous abortions, 15 children with malformations including hypoplastic nails and shortened fingers, microtia with cleft lip and palate, microtia alone and neonatal death with multiple malformations [84].

A 2008 report suggested the hypothesis that utero exposure to mycophenolate mofetil can cause a characteristic phenotype and suggests the existence of a mycophenolate-associated embryopathy, whose main features are: cleft lip and palate, microtia with atresia of external auditory canal, micrognathia and hypertelorism. Ocular anomalies, corpus callosum agenesis, heart defects, kidney malformations and diaphragmatic hernia may be part of the phenotypic spectrum of this embryopathy [88-90].

\section{Future Perspective for Pregnancy in CKD}

In conclusion, it is important to consider that most of the literature on this topic includes a single center, is retrospective, and uncontrolled, especially for the measurement of renal function. Moreover, data on pregnancy outcomes are missing on specific renal diseases.

Despite these limits, we have to recognize the increasing evidence that the degree of renal insufficiency, rather than the underlying renal diagnosis, is the primary determinant of outcome. In the presence of CKD, especially in glomerulonephritis such as SLE, the nephrologist should be aware of the high risks for renal loss, pregnancy complications, preterm delivery and uterine growth retardation.

Therefore, we think that the report of any pregnancy in specific registries may not only be useful but necessary to develop our knowledge and achieve successful medical management of the mother and the infant in the presence of CKD.

\section{Acknowledgement}

We thank Chiara Di Giorgio for linguistic revision of the article.

\section{References}

1 Williams D, Davison J: Chronic kidney disease in pregnancy. BMJ 2008;336:211-215.

$\checkmark 2$ Hou S: Pregnancy in chronic renal insufficiency and end-stage renal disease. Am J Kidney Dis 1999;33:235-252.

-3 Baylis C: Glomerular filtration and volume regulation in gravid animal models. Baillieres Clin Obstet Gynaecol 1994;8:235-264.

4 Maynard SE, Thadhani R: Pregnancy and the kidney. J Am Soc Nephrol 2009;20:1422.

5 Smith MC, Moran P, Ward MK, Davison JM: Assessment of glomerular filtration rate during pregnancy using the MDRD formula. BJOG 2008;115:109-112.

-6 Alper AB, Yi Y, Webber LS, Pridjian G, Mumuney AA, Saade G, Morgan J, Nuwayhid B, Belfort M, Puschett J: Estimation of glomerular filtration rate in preeclamptic patients. Am J Perinatol 2007;24:569-574.
7 Rule AD, Larson TS, Bergstralh EJ, Slezak 10 Purdy LP, Hantsch CE, Molitch ME, Metzger JM, Jacobsen SJ, Cosio FG: Using serum creatinine to estimate glomerular filtration rate: accuracy in good health and in chronic kidney disease. Ann Intern Med 2004;141: 929-937.

8 Eknoyan G, Hostetter T, Bakris GL, Hebert L, Levey AS, Parving HH, Steffes MW, Toto R: Proteinuria and other markers of chronic kidney disease: a position statement of the national kidney foundation (NKF) and the national institute of diabetes and digestive and kidney diseases (NIDDK). Am J Kidney Dis 2003;42:617-622.

9 Imbasciati E, Pardi G, Capetta P, Ambroso G, Bozzetti P, Pagliari B, Ponticelli C: Pregnancy in women with chronic renal failure. Am J Nephrol 1986;6:193-198. BE, Phelps RL, Dooley SL, Hou SH: Effect of pregnancy on renal function in patients with moderate-to-severe diabetic renal insufficiency. Diabetes Care 1996;19:1067-1074.

11 Jones DC, Hayslett JP: Outcome of pregnancy in women with moderate or severe renal insufficiency. N Engl J Med 1996;335:226232 .

12 Sanders CL, Lucas MJ: Renal disease in pregnancy. Obstet Gynecol Clin North Am 2001; 28:593-600, vii.

13 Imbasciati E, Gregorini G, Cabiddu G, Gammaro L, Ambroso G, Del Giudice A, Ravani P: Pregnancy in CKD stages 3 to 5 : fetal and maternal outcomes. Am J Kidney Dis 2007; 49:753-762.

14 Piccoli GB, Attini R, Vasario E, Conijn A, Biolcati M, D’Amico F, Consiglio V, Bontempo S, Todros T: Pregnancy and chronic kidney disease: a challenge in all CKD stages. Clin J Am Soc Nephrol 2010;5:844-855. 
$>15$ McArdle A, Maduwegedera D, Moritz K, 27 Askie LM, Duley L, Henderson-Smart DJ, Flower RL, Denton KM, Roberts CT: Chronic maternal hypertension affects placental gene expression and differentiation in rabbits. J Hypertens 2010;28:959-968.

- 16 McArdle AM, Roberts CT, Maduwegedera D, Flower RL, Denton KM: Chronic maternal hypertension characterized by renal dysfunction is associated with reduced placental blood flow during late gestation in rabbits. Am J Physiol Regul Integr Comp Physiol 2010;298:R1043-R1049.

17 Laube GF, Kemper MJ, Schubiger G, Neuhaus TJ: Angiotensin-converting enzyme inhibitor fetopathy: long-term outcome. Arch Dis Child Fetal Neonatal Ed 2007;92:F402F403.

18 Alwan S, Polifka JE, Friedman JM: Angiotensin II receptor antagonist treatment during pregnancy. Birth Defects Res A Clin Mol Teratol 2005;73:123-130.

19 Baumwell S, Karumanchi SA: Pre-eclampsia: clinical manifestations and molecular mechanisms. Nephron Clin Pract 2007; 106:c72-c81.

20 Cornelis T, Odutayo A, Keunen J, Hladunewich M: The kidney in normal pregnancy and preeclampsia. Semin Nephrol 2011;31: 4-14.

-21 Maynard SE, Min JY, Merchan J, Lim KH, Li J, Mondal S, Libermann TA, Morgan JP, Sellke FW, Stillman IE, Epstein FH, Sukhatme VP, Karumanchi SA: Excess placental soluble fms-like tyrosine kinase 1 (sFlt1) may contribute to endothelial dysfunction, hypertension, and proteinuria in preeclampsia. J Clin Invest 2003;111:649-658.

-22 Levine RJ, Lam C, Qian C, Yu KF, Maynard SE, Sachs BP, Sibai BM, Epstein FH, Romero R, Thadhani R, Karumanchi SA: Soluble endoglin and other circulating antiangiogenic factors in preeclampsia. N Engl J Med 2006; 355:992-1005.

-23 Levine RJ, Maynard SE, Qian C, Lim KH, England LJ, Yu KF, Schisterman EF, Thadhani R, Sachs BP, Epstein FH, Sibai BM, Sukhatme VP, Karumanchi SA: Circulating angiogenic factors and the risk of preeclampsia. N Engl J Med 2004;350:672-683.

-24 Moore Simas TA, Crawford SL, Solitro MJ, Frost SC, Meyer BA, Maynard SE: Angiogenic factors for the prediction of preeclampsia in high-risk women. Am J Obstet Gynecol 2007;197:244-248.

25 Vikse BE, Irgens LM, Leivestad T, Skjaerven $\mathrm{R}$, Iversen BM: Preeclampsia and the risk of end-stage renal disease. N Engl J Med 2008; 359:800-809.

26 Gilbert JS, Verzwyvelt J, Colson D, Arany M, Karumanchi SA, Granger JP: Recombinant vascular endothelial growth factor $121 \mathrm{infu}$ sion lowers blood pressure and improves renal function in rats with placentalischemiainduced hypertension. Hypertension 2010; 55:380-385. Stewart LA: Antiplatelet agents for prevention of pre-eclampsia: a meta-analysis of individual patient data. Lancet 2007;369:17911798.

28 Limardo M, Imbasciati E, Ravani P, Surian M, Torres D, Gregorini G, Magistroni R, Casellato D, Gammaro L, Pozzi C: Pregnancy and progression of IgA nephropathy: results of an Italian multicenter study. Am J Kidney Dis 2010;56:506-512.

-29 Goldstein AR, White RH, Akuse R, Chantler C: Long-term follow-up of childhood Henoch-Schönlein nephritis. Lancet 1992;339: 280-282.

30 Ronkainen J, Nuutinen M, Koskimies O: The adult kidney 24 years after childhood $\mathrm{He}$ noch-Schönlein purpura: a retrospective cohort study. Lancet 2002;360:666-670.

- 31 Kalmantis K, Daskalakis G, Iavazzo C, Vranos A, Mesogitis S, Antsaklis A: HenochSchönlein purpura in pregnancy. J Obstet Gynaecol 2008;28:403-405.

32 Keeling SO, Oswald AE: Pregnancy and rheumatic disease: 'by the book' or 'by the doc'. Clin Rheumatol 2009;28:1-9.

33 Day CJ, Lipkin GW, Savage CO: Lupus nephritis and pregnancy in the 21st century. Nephrol Dial Transplant 2009;24:344-347.

34 Clowse ME: Lupus activity in pregnancy. Rheum Dis Clin North Am 2007;33:237-52, v.

35 Clowse ME, Jamison M, Myers E, James AH: A national study of the complications of lupus in pregnancy. Am J Obstet Gynecol 2008;199:127.e1-6.

-36 Wagner SJ, Craici I, Reed D, Norby S, Bailey $\mathrm{K}$, Wiste HJ, Wood CM, Moder KG, Liang KP, Liang KV, Rose C, Rozkos T, Sitina M, Grande JP, Garovic VD: Maternal and foetal outcomes in pregnant patients with active lupus nephritis. Lupus 2009;18:342-347.

- 37 Carmona F, Font J, Moga I, Lazaro I, Cervera $\mathrm{R}, \mathrm{Pac} \mathrm{V}$, Balasch J: Class III-IV proliferative lupus nephritis and pregnancy: a study of 42 cases. Am J Reprod Immunol 2005;53:182188 .

- 38 Bolignano D, Coppolino G, Crasci E, Campo S, Aloisi C, Buemi M: Pregnancy in uremic patients: an eventful journey. J Obstet Gynaecol Res 2008;34:137-143.

39 Vidaeff AC, Yeomans ER, Ramin SM: Pregnancy in women with renal disease. 1 . General principles. Am J Perinatol 2008;25:385397.

40 Souqiyyeh MZ, Huraib SO, Saleh AG, Aswad $S$ : Pregnancy in chronic hemodialysis patients in the Kingdom of Saudi Arabia. Am J Kidney Dis 1992;19:235-238.

41 Hou SH: Frequency and outcome of pregnancy in women on dialysis. Am J Kidney Dis 1994;23:60-63.

42 Bagon JA, Vernaeve H, De Muylder X, Lafontaine JJ, Martens J, Van Roost G: Pregnancy and dialysis. Am J Kidney Dis 1998;31:756765.
43 Toma H, Tanabe K, Tokumoto T, Kobayashi C, Yagisawa T: Pregnancy in women receiving renal dialysis or transplantation in Japan: a nationwide survey. Nephrol Dial Transplant 1999;14:1511-1516.

44 Roxe DM, McLaughlin MM: Reproductive capacity in female patients on chronic hemodialysis. Int J Artif Organs 1984;7:249-250.

45 Redrow M, Cherem L, Elliott J, Mangalat J, Mishler RE, Bennett WM, Lutz M, Sigala J, Byrnes J, Phillipe M: Dialysis in the management of pregnant patients with renal insufficiency. Medicine (Baltimore) 1988;67:199_ 208

46 Giatras I, Levy DP, Malone FD, Carlson JA, Jungers P: Pregnancy during dialysis: case report and management guidelines. Nephrol Dial Transplant 1998;13:3266-3272.

-47 Romao JE, Jr., Luders C, Kahhale S, Pascoal IJ, Abensur H, Sabbaga E, Zugaib M, Marcondes M: Pregnancy in women on chronic dialysis. A single-center experience with 17 cases. Nephron 1998;78:416-422.

48 Nakabayashi M, Adachi T, Itoh S, Kobayashi M, Mishina J, Nishida H: Perinatal and infant outcome of pregnant patients undergoing chronic hemodialysis. Nephron 1999;82: 27-31.

49 Reister F, Reister B, Heyl W, Riehl J, Schroder W, Mann H, Rath W: Dialysis and pregnancy - A case report and review of the literature. Ren Fail 1999;21:533-539.

50 Barua M, Hladunewich M, Keunen J, Pierratos A, McFarlane P, Sood M, Chan CT: Successful pregnancies on nocturnal home hemodialysis. Clin J Am Soc Nephrol 2008;3: 392-396.

51 Bamberg C, Diekmann F, Haase M, Budde K, Hocher B, Halle H, Hartung J: Pregnancy on intensified hemodialysis: fetal surveillance and perinatal outcome. Fetal Diagn Ther 2007;22:289-293.

52 Haase M, Morgera S, Bamberg C, Halle H, Martini S, Hocher B, Diekmann F, Dragun D, Peters H, Neumayer HH, Budde K: A systematic approach to managing pregnant dialysis patients - The importance of an intensified haemodiafiltration protocol. Nephrol Dial Transplant 2005;20:2537-2542.

53 Villa G, Montagna G, Segagni S: Pregnancy in chronic dialysis. A case report and a review of the literature. G Ital Nefrol 2007;24: 132-140.

54 Gangji AS, Windrim R, Gandhi S, Silverman JA, Chan CT: Successful pregnancy with nocturnal hemodialysis. Am J Kidney Dis 2004;44:912-916.

55 Oosterhof H, Navis GJ, Go JG, Dassel AC, de Jong PE, Aarnoudse JG: Pregnancy in a patient on chronic haemodialysis: fetal monitoring by Doppler velocimetry of the umbilical artery. Br J Obstet Gynaecol 1993;100: $1140-1141$. 
-56 Stratta P, Canavese C, Giacchino F, Mesiano P, Quaglia M, Rossetti M: Pregnancy in kidney transplantation: satisfactory outcomes and harsh realities. J Nephrol 2003;16:792806.

57 Holley JL, Reddy SS: Pregnancy in dialysis patients: a review of outcomes, complications, and management. Semin Dial 2003;16: 384-388.

58 Giofre F, Pugliese C, Alati G, Messina A, Tramontana $\mathrm{D}$ : Three successive pregnancies in a patient with chronic renal disease progressing from chronic renal dysfunction through to institution of dialysis during pregnancy and then on to maintenance dialysis. Nephrol Dial Transplant 2007;22: 1236-1240.

-59 Rizzoni G, Ehrich JH, Broyer M, Brunner FP, Brynger H, Fassbinder W, Geerlings W, Selwood NH, Tufveson G, Wing AJ: Successful pregnancies in women on renal replacement therapy: report from the EDTA Registry. Nephrol Dial Transplant 1992;7:279-287.

-60 Tuot D, Gibson S, Caughey AB, Frassetto LA: Intradialytic hyperalimentation as adjuvant support in pregnant hemodialysis patients: case report and review of the literature. Int Urol Nephrol 2010;42:233-237.

61 Hou S, Firanek C: Management of the pregnant dialysis patient. Adv Ren Replace Ther 1998;5:24-30.

62 Chang H, Miller MA, Bruns FJ: Tidal peritoneal dialysis during pregnancy improves clearance and abdominal symptoms. Perit Dial Int 2002;22:272-274.

-63 Gómez Vázquez JA, Martínez Calva IE, Mendíola Fernández R, Escalera León V, Cardona M, Noyola H: Pregnancy in endstage renal disease patients and treatment with peritoneal dialysis: report of two cases. Perit Dial Int 2007;27:353-358.

64 Sibanda N, Briggs JD, Davison JM, Johnson RJ, Rudge CJ: Pregnancy after organ transplantation: a report from the UK Transplant pregnancy registry. Transplantation 2007; 83:1301-1307.

65 First MR, Combs CA, Weiskittel P, Miodovnik M: Lack of effect of pregnancy on renal allograft survival or function. Transplantation 1995;59:472-476.

-66 Miranda CT, Melaragno C, Camara NO, Pacheco-Silva A, Medina-Pestana PJ: Adverse effects of pregnancy on renal allograft function. Transplant Proc 2002;34:506-507.
67 Sturgiss SN, Davison JM: Effect of pregnancy on the long-term function of renal allografts: an update. Am J Kidney Dis 1995; 26:54-56.

68 Kim HW, Seok HJ, Kim TH, Han DJ, Yang WS, Park SK: The experience of pregnancy after renal transplantation: pregnancies even within postoperative 1 year may be tolerable. Transplantation 2008;85:1412-1419.

69 Armenti VT, Radomski JS, Moritz MJ, Gaughan WJ, Hecker WP, Lavelanet A, McGrory CH, Coscia LA: Report from the National Transplantation Pregnancy Registry (NTPR): outcomes of pregnancy after transplantation. Clin Transpl 2004:103-114.

70 Davison JM, Bailey DJ: Pregnancy following renal transplantation. J Obstet Gynaecol Res 2003;29:227-233.

71 Davison JM, Milne JE: Pregnancy and renal transplantation. Br J Urol 1997;80(suppl 1): 29-32.

72 Report of the National High Blood Pressure Education Program Working Group on high blood pressure in pregnancy. Am J Obstet Gynecol 2000;183:S1-S22.

73 McKay DB, Josephson MA: Pregnancy in recipients of solid organs - Effects on mother and child. N Engl J Med 2006;354:12811293.

74 Le Ray C, Coulomb A, Elefant E, Frydman R, Audibert F: Mycophenolate mofetil in pregnancy after renal transplantation: a case of major fetal malformations. Obstet Gynecol 2004;103:1091-1094.

-75 Guardia O, Rial MC, Casadei D: Pregnancy under sirolimus-based immunosuppression. Transplantation 2006;81:636.

76 Chen X, He J, Ding Y, Zeng L, Gao R, Cheng $S$, Liu X, Wang Y: The role of MTOR in mouse uterus during embryo implantation. Reproduction 2009;138:351-356.

77 Gaughan WJ, Moritz MJ, Radomski JS, Burke JF Jr, Armenti VT: National Transplantation Pregnancy Registry: report on outcomes in cyclosporine-treated female kidney transplant recipients with an interval from transplant to pregnancy of greater than five years. Am J Kidney Dis 1996;28:266269.

78 Armenti VT, Moritz MJ, Davison JM: Drug safety issues in pregnancy following transplantation and immunosuppression: effects and outcomes. Drug Saf 1998;19:219-232.

-79 Jain AB, Shapiro R, Scantlebury VP, Potdar S, Jordan ML, Flohr J, Marcos A, Fung JJ: Pregnancy after kidney and kidney-pancreas transplantation under tacrolimus: a single center's experience. Transplantation 2004; 77:897-902.
80 European best practice guidelines for renal transplantation. Section IV: long-term management of the transplant recipient. IV.10. Pregnancy in renal transplant recipients. Nephrol Dial Transplant 2002;17(suppl 4):50-55.

81 Flechner SM, Katz AR, Rogers AJ, Van BC, Kahan BD: The presence of cyclosporine in body tissues and fluids during pregnancy. Am J Kidney Dis 1985;5:60-63.

82 Shaheen FA, al-Sulaiman MH, al-Khader AA: Long-term nephrotoxicity after exposure to cyclosporine in utero. Transplantation 1993;56:224-225.

83 Jain A, Venkataramanan R, Fung JJ, Gartner JC, Lever J, Balan V, Warty V, Starzl TE: Pregnancy after liver transplantation under tacrolimus. Transplantation 1997;64:559565.

84 Farley DE, Shelby J, Alexander D, Scott JR: The effect of two new immunosuppressive agents, FK506 and didemnin B, in murine pregnancy. Transplantation 1991;52:106110.

85 Fein A, Vechoropoulos M, Nebel L: Cyclosporin-induced embryotoxicity in mice. Biol Neonate 1989;56:165-173.

86 Mason RJ, Thomson AW, Whiting PH, Gray ES, Brown PA, Catto GR, Simpson JG: Cyclosporine-induced fetotoxicity in the rat. Transplantation 1985;39:9-12.

88 Perez-Aytes A, Ledo A, Boso V, Saenz P, Roma E, Poveda JL, Vento M: In utero exposure to mycophenolate mofetil: a characteristic phenotype? Am J Med Genet A 2008; 146A:1-7.

88 Merlob P, Stahl B, Klinger G: Tetrada of the possible mycophenolate mofetil embryopathy: a review. Reprod Toxicol 2009;28:105108 .

89 Anderka MT, Lin AE, Abuelo DN, Mitchell AA, Rasmussen SA: Reviewing the evidence for mycophenolate mofetil as a new teratogen: case report and review of the literature. Am J Med Genet A 2009;149A:1241-1248.

-90 Parisi MA, Zayed H, Slavotinek AM, Rutledge JC: Congenital diaphragmatic hernia and microtia in a newborn with mycophenolate mofetil (MMF) exposure: phenocopy for Fryns syndrome or broad spectrum of teratogenic effects? Am J Med Genet A 2009. 149A:1237-1240. 